\title{
Does a pay-for-performance program for primary care physicians alleviate health inequity in childhood vaccination rates?
}

\author{
Alan Katz ${ }^{1,2^{*}}$, Jennifer Emily Enns ${ }^{1,2}$, Dan Chateau ${ }^{1,2}$, Lisa Lix ${ }^{1,2}$, Doug Jutte ${ }^{1,3}$, Jeanette Edwards ${ }^{4}$, Marni Brownell ${ }^{1,2}$, \\ Colleen Metge ${ }^{1,5}$, Nathan Nickel ${ }^{1,2}$, Carole Taylor ${ }^{1}$, Elaine Burland ${ }^{1}$ and The PATHS Equity Team ${ }^{1}$
}

\begin{abstract}
Introduction: Childhood vaccination rates in Manitoba populations with low socioeconomic status (SES) fall significantly below the provincial average. This study examined the impact of a pay-for-performance (P4P) program called the Physician Integrated Network (PIN) on health inequity in childhood vaccination rates.

Methods: The study used administrative data housed at the Manitoba Centre for Health Policy. We included all children born in Manitoba between 2003 and 2010 who were patients at PIN clinics receiving P4P funding matched with controls at non-participating clinics. We examined the rate of completion of the childhood primary vaccination series by age 2 across income quintiles (Q1-Q5). We estimated the distribution of income using the Gini coefficient, and calculated concentration indices for vaccination to determine whether the P4P program altered SES-related differences in vaccination completion. We compared these measures between study cohorts before and after implementation of the P4P program, and over the course of the P4P program in each cohort.
\end{abstract}

Results: The PIN cohort included 6,185 children. Rates of vaccination completion at baseline were between 0.53 (Q1) and 0.69 (Q5). Inequality in income distribution was present at baseline and at study end in PIN and control cohorts. SES-related inequity in vaccination completion worsened in non-PIN clinics (difference in concentration index 0.037; $95 \% \mathrm{Cl} 0.013,0.060$ ), but remained constant in P4P-funded clinics (difference in concentration index $0.006 ; 95 \% \mathrm{Cl} 0.008,0.021)$.

Conclusions: The P4P program had a limited impact on vaccination rates and did not address health inequity.

Keywords: Health equity, Income inequality, Childhood, Immunization, Vaccination, Manitoba, Canada

\section{Introduction}

Inequity in health outcomes is a global challenge that creates economic losses and health care burdens, such as loss of productivity and tax payments, higher welfare payments and health care costs [1-7]. Inequity in child health often translates into chronically poorer health in adulthood, adding further burdens on the health care system and the population [8]. Measures associated with socioeconomic status (SES), such as income, employment, and education, are only a few of the social determinants of health [2].

\footnotetext{
*Correspondence: alan_katz@cpe.umanitoba.ca

${ }^{1}$ Manitoba Centre for Health Policy, 408-727 McDermot Ave, Winnipeg, MB R3E 3P5, Canada

${ }^{2}$ Department of Community Health Sciences, University of Manitoba,

S113-750 Bannatyne Ave, Winnipeg, MB R3E OW3, Canada

Full list of author information is available at the end of the article
}

However, social programs addressing some of these determinants have been shown to be effective at alleviating health inequity in Canada [9] and globally [10]. Researchers at the Manitoba Centre for Health Policy (MCHP) are currently conducting multiple evaluations as part of the PATHS (Pathways To Health and Social Equity for Children) program of research, with the aim of determining the impact of established programs on health and social inequity in children in Manitoba [11]. Among these programs is the Physician Integrated Network (PIN), a primary care renewal initiative developed by the Ministry of Health in Manitoba, which aimed to improve primary care outcomes by providing clinics with pay-for-performance (P4P) funding [12].

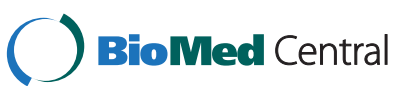


The PIN program provided funding to clinics in Manitoba for meeting quality of care targets on selected clinical process indicators, including meeting childhood vaccination targets. The provincially recommended childhood vaccination program in Manitoba follows a vaccination schedule that stipulates a primary series be administered by age 2 [13]. The vaccinations have been shown to afford valuable protection against mortality from infectious disease in Canada [14], defending against all-cause mortality [15] and limiting exacerbation of chronic diseases such as asthma attacks [16, 17]. However, analyses of provincial vaccination data from 2002/03 and 2007/08 have demonstrated that childhood vaccination rates in lowSES Manitoba populations fall significantly below the provincial average [13]. Inequity in vaccination exists in other Canadian provinces and globally, and is associated with factors such as SES [18-24], household income $[19,21,25,26]$, mother's knowledge about vaccinations [23, 27], length of maternity leave [23], and access to transportation [28].

Although the PIN program aimed to improve the overall quality of primary care and did not specifically target low-SES Manitobans, there is concern that P4P programs operating within the current pattern of health inequity can widen the socioeconomic gap. It has long been recognized that inequities left unaddressed have damaging effects on health outcomes in vulnerable populations [10]. Therefore, we evaluated the PIN P4P program to determine whether it alleviated SES-based inequity in childhood vaccination rates in Manitoba.

\section{Methods}

Administrative data sources

The PATHS Data Resource [11] is a de-identified collection of data which is part of the Population Health Research Data Repository (the Repository) housed at MCHP, University of Manitoba. The PATHS resource was created by linking information across several databases of population-based individual-level data using scrambled personal identifying numbers, such that it comprises health and social services use data for over $99 \%$ of the children in Manitoba. In this study, we used three datasets within the PATHS resource: the Manitoba Immunization Monitoring System which contains vaccination dates and identifiers; claims for physician visits and tests ordered; and the Manitoba Health Registry which includes demographic data (e.g., sex, age, postal code) on virtually every child residing in Manitoba. The validity of the data included in the PATHS resource have been well documented [29-32]. The study was approved by the University of Manitoba Health Research Ethics Board (HREB) and the Manitoba Health Information Privacy Committee (HIPC).
Income quintiles were constructed using public-use census data for each dissemination area ( 400-700 individuals) in Manitoba based on the postal code of the child at age 2 . The dissemination areas were sorted by average income and divided into quintiles of equal population size. About $1 \%$ of individuals in Manitoba were excluded from the income quintiles, because their postal code did not link with a dissemination area, their dissemination area had a suppressed average household income, or they lived in a dissemination area where $90 \%$ or more of the population was institutionalized (i.e., personal care home, prison).

\section{Study cohorts}

The PIN program was implemented in two phases: Phase 1 was launched in 2007 with the participation of four primary care clinics, and eight additional clinics were recruited for Phase 2 in 2008. The twelve clinics were distributed across Manitoba regional health authorities (RHAs) and included 170 physicians with over 180,000 patients assigned to their care during the period of study [33]. P4P funding was based on 15 care provision process indicators, including childhood immunizations, with quarterly extracts from the clinic electronic medical record providing evidence of clinical practice.

The development of the study cohorts is described in Fig. 1. PIN clinics first identified their core patients in their electronic medical records using an established algorithm [33]. Children were included in the PIN clinic cohort if they were born in Manitoba between 2003 and 2010, were continuously registered with Manitoba Health, Healthy Living and Seniors (MHHLS) up to their second birthday, and were identified as core PIN clinic patients. We matched these patients to non-PIN clinic controls by RHA of residence, income quintile and birth year.

\section{Primary outcomes}

We determined the rate of vaccination completion by income quintile in each cohort by counting the number of vaccine doses children had received by the age of 2 and comparing these to the Manitoba Immunization Guidelines [12]. To measure the distribution of our health outcome (completion of vaccination) across income quintiles, we calculated the concentration index for the five-year study period, providing an estimate of SES-related inequity $[34,35]$. The concentration index is estimated from the concentration curve, which is based on the proportion of people in a population at different SES levels with a particular outcome (in this case, vaccination). The concentration index is determined by calculating the area between the concentration curve and the line of equity (representing $100 \%$ equal distribution of vaccination among SES quintiles), and thereby allows an estimation of SES-related inequity with values 


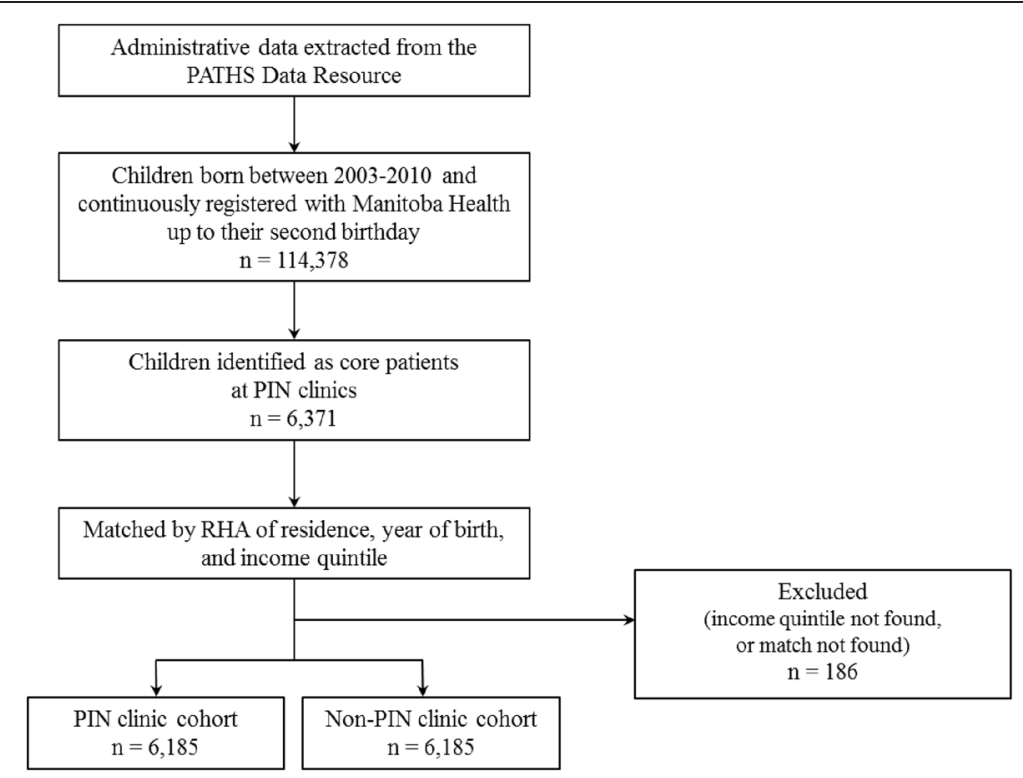

Fig. 1 Flowchart depicting the creation of study cohorts from PATHS Data Resource administrative data

ranging from -1 to +1 . A concentration index with a value of 0 would indicate that vaccination was distributed evenly across income quintiles. A concentration index approaching +1 would indicate that vaccination is concentrated among the wealthy quintiles, while a value approaching -1 would mean it is more common among the poor quintiles. Concentration indices were calculated for PIN and matched non-PIN cohorts before and after the PIN program was implemented to assess whether the PIN program was associated with reduced SESrelated inequity in vaccinations.

Changes in concentration indices for vaccination could be influenced by corresponding changes in underlying income inequality [36]. We therefore estimated the Gini coefficient to quantify the distribution of family income over the study period [34, 35, 37]. The Gini is estimated from the Lorenz curve, a measure of wealth distribution within a population that demonstrates the percentage of people falling within a certain range of income. The Gini represents the area between the Lorenz curve and $100 \%$ equality in income distribution, allowing the degree of income inequality to be quantified with values falling between 0 (equal distribution of income across the population) and 1 (absolute inequality, where all income belongs to a single individual). Gini coefficients were calculated before and after the PIN program was implemented in both PIN and non-PIN cohorts to determine whether income inequality changed over time in the study population.

We also estimated the Kakwani Progressivity Index (KPI). The KPI is defined as the difference between the concentration index (health inequity) and the Gini coefficient (income distribution), and ranges from -2 to 1
[38]. For our study, the KPI was modified (mKPI) so that $\mathrm{mKPI}=$ Gini $-\mid$ concentration index $\mid$. Hence, a positive mKPI would occur when health inequity was less than income inequality, i.e., given the unequal distribution of income across the population (indicated by the Gini coefficient), health inequity is less than would be expected. Conversely, a negative mKPI would signify that health inequity was greater than expected, taking into account the underlying income inequality. Measures of precision (e.g., standard errors, $95 \%$ confidence intervals [CI]) were estimated for the concentration indices, Gini coefficients and mKPIs using bootstrapping [39]. All data analyses for this paper were generated using SAS software, Version 9.3 [40].

\section{Results}

Figure 1 shows the development of the study cohorts, and Table 1 lists the demographics for the children included in the study cohorts. The children were matched by birth year, RHA of residence, and income quintile; and although we didn't match for sex, the proportions were very similar between groups.

Figure 2 shows the rates of vaccination completion by income quintile for the study cohorts before and after the PIN program. Children in the higher income quintiles were more likely to have completed the primary vaccination series than those in the lower income quintiles. In the non-PIN clinic cohort, vaccination completion rates declined in children in Q2 and Q3 over the course of the PIN program.

Table 2 presents measures of the distribution of income and SES-related differences in vaccination for the study cohorts before and after implementation of the 
Table 1 Demographics of the study population

\begin{tabular}{|c|c|}
\hline & $\begin{array}{l}\text { PIN clinic cohort } \\
\text { No. (\%) }\end{array}$ \\
\hline$N$ & 6,185 \\
\hline \multicolumn{2}{|l|}{ Birth Year } \\
\hline 2003 & $117(1.9)$ \\
\hline 2004 & $610(9.9)$ \\
\hline 2005 & $956(15.5)$ \\
\hline 2006 & 1, $494(24.2)$ \\
\hline 2007 & $1,548(25.0)$ \\
\hline 2008 & $913(14.8)$ \\
\hline 2009 & $547(8.8)$ \\
\hline \multicolumn{2}{|l|}{ Sex } \\
\hline Male & $3,182(51.4)$ \\
\hline Female & $3,003(48.6)$ \\
\hline \multicolumn{2}{|l|}{ RHA } \\
\hline Interlake-Eastern & $115(1.9)$ \\
\hline Northern & $20(0.3)$ \\
\hline Southern & 4, $026(65.1)$ \\
\hline Prairie Mountain (Western) & 1, $036(16.8)$ \\
\hline Winnipeg/Brandon & $988(16.0)$ \\
\hline \multicolumn{2}{|l|}{ Income Quintile } \\
\hline Q1 (lowest) & $865(14.0)$ \\
\hline Q2 & 1, $132(18.3)$ \\
\hline Q3 & $1,738(28.1)$ \\
\hline Q4 & 1, $538(24.9)$ \\
\hline Q5 (highest) & $912(14.7)$ \\
\hline
\end{tabular}

$R H A$ regional health authority

${ }^{\mathrm{a}}$ The PIN and non-PIN clinic cohorts were matched on birth year, RHA and income quintile. In the non-PIN clinic cohort, there were 3,161 (51.1\%) males and 3,024 (48.9\%) females

PIN program. At baseline, inequality in income distribution existed in both groups, as the Gini coefficients were significantly higher than 0 in the PIN clinics and nonPIN clinics. Concentration indices for the PIN clinics and the non-PIN clinics were significantly higher than 0 , indicating that there was health inequity in vaccination present in both groups, that is, individuals with higher income were more likely to be vaccinated than those with lower income. The mKPI in both groups was also significantly greater than 0 at baseline, indicating that although health inequity was present, it was less than expected given the underlying income inequality.

At the end of the 5-year PIN program, Gini coefficients in the PIN clinics and non-PIN clinics remained significantly higher than 0 , signifying that a significant difference in income distribution between the two groups persisted. Concentration indices for the PIN clinics and the nonPIN clinics remained significantly higher than 0 , indicating that health inequity in vaccination continued in both groups after the PIN intervention. The mKPI showed that health inequity was less than expected when accounting for the underlying income inequality in these groups.

In Table 3, we show the changes in health equity measures between the start and the end of the 5-year PIN program (i.e., difference over time). The Gini did not change significantly in either cohort over the course of the PIN program. The concentration index for the nonPIN clinic cohort increased significantly, indicating that health inequity in vaccination completion worsened over time in this cohort. In other words, in clinics that did not have P4P funding, the gap in vaccination rates between wealthy and low-income families widened over the study period. In this same cohort, mKPI decreased significantly over time, indicating that by the end of the study period, any factors mitigating the impact of the income inequality on health inequality had weakened.

\section{Discussion}

The findings of this study suggest that the PIN program helped to maintain the pre-intervention level of inequity in childhood vaccination rates by the age of 2. Although income distribution remained unequal in the both the PIN and non-PIN groups throughout the course of the P4P intervention, inequities in vaccination across income quintiles worsened in non-PIN clinics while remaining stable in PIN clinics. We expected to see a decrease in health inequity in the PIN clinics, but this was offset by the health inequity increase in the non-PIN clinics.

In the last decade, P4P programs have become a popular method of encouraging improved primary health care, although it is still uncertain how they impact patient care and disease management [41, 42]. With regard to vaccinations specifically, these programs have produced mixed results. A study in Ontario demonstrated that a P4P program had no effect on childhood immunizations, and only modest effects on other indicators such as mammograms and colorectal cancer screening [43]. An analysis in the United States measured the effect of P4P programs on health care quality, including childhood vaccination [44]; however, the study failed to find evidence that P4P initiatives brought about major improvements in quality of care. Another study found that P4P funding modestly improved childhood vaccination rates [45].

To our knowledge, our study is the first to examine whether a P4P intervention can effectively alleviate SESrelated health inequities in vaccination. Our findings suggest that in the absence of a P4P funding initiative, inequity in vaccination completion increased in the general population. Although the PIN program mitigated the increasing negative effect of low SES on vaccination during the study period, the program did not address 


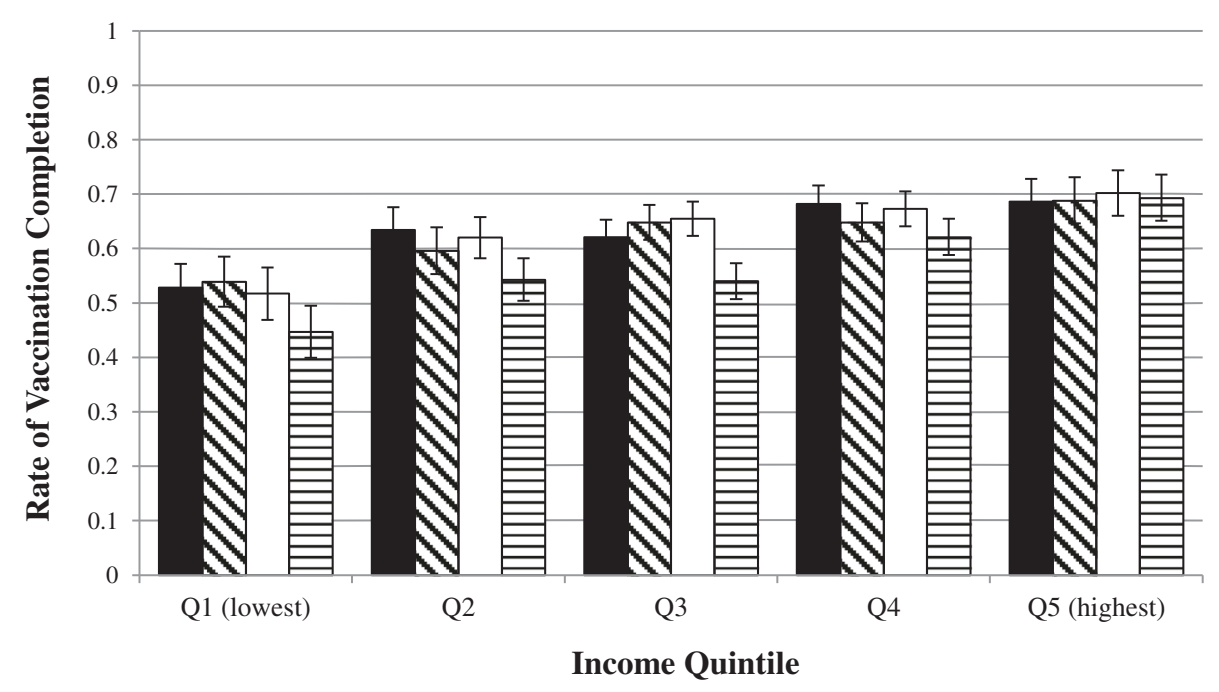

- PIN Clinics (prior to PIN)
$\square$ PIN Clinics (after PIN)

Non-PIN Clinics (prior to PIN)

曰Non-PIN Clinics (after PIN)

Fig. 2 Rates of vaccination completion at age 2 by income quintile. Error bars indicate $95 \% \mathrm{Cls}$

the pre-existing health inequity. The social determinants of health, including SES, have a direct effect on the health of individuals and populations, and disparities in health affect the health status of the overall population $[46,47]$. Although P4P funding models may provide incentive to clinicians to improve the quality of care they offer to patients, other research has shown that they do little to address health equity gaps [48-50], unless the equity gap is extreme. Our results demonstrated a positive effect compared to the control group, but did not show an absolute reduction in inequity. The relatively small gap in vaccination completion rates in Manitoba (Fig. 2) may have contributed to the PIN program's lack of effect on health equity, since there is more potential for improving low-SES patient outcomes where a large equity gap exists.

\section{Strengths and limitations}

Strengths of our study include the ability to link administrative data across several databases, allowing us to capture virtually all of the eligible population for our study cohort, including rural and urban populations. Although our findings are specific to the primary care renewal initiatives implemented in the province of Manitoba, the inclusion of different geographic regions lends generalizability to the results for the entire population of the province. The analysis was limited by the use of area-level income data. However, studies have shown that area-level measurements, such as those collected from dissemination areas, provide a good approximation of individual-level SES [51]. Although we detected a significant gap in health equity over time, the absolute change in the concentration index between groups was

Table 2 Measures of income distribution and SES-related inequity in vaccination completion

\begin{tabular}{lllll}
\hline & & $\begin{array}{l}\text { PIN clinics } \\
(95 \% \mathrm{Cl})\end{array}$ & $\begin{array}{l}\text { Non-PIN clinics } \\
(95 \% \mathrm{Cl})\end{array}$ & $\begin{array}{l}\text { Difference between groups } \\
(95 \% \mathrm{Cl})\end{array}$ \\
\hline Prior to PIN & Gini & $0.135(0.127,0.142)$ & $0.154(0.147,0.160)$ & $0.019(0.010,0.028)$ \\
& Conc index & $0.036(0.019,0.053)$ & $0.031(0.016,0.045)$ & $0.005(-0.011,0.022)$ \\
& KPI & $0.099(0.080,0.117)$ & $0.123(0.108,0.138)$ & $-0.024(-0.048,-0.001)$ \\
After PIN & Gini & $0.136(0.129,0.143)$ & $0.152(0.146,0.158)$ & $0.016(0.006,0.025)$ \\
& Conc index & $0.042(0.027,0.057)$ & $0.067(0.048,0.086)$ & $0.025(0.002,0.049)$ \\
& KPI & $0.094(0.077,0.111)$ & $0.084(0.066,0.103)$ & $0.010(-0.008,0.027)$ \\
\hline
\end{tabular}


Table 3 Changes in income inequality and health inequity measures over time

\begin{tabular}{lll}
\hline & PIN clinics & Non-PIN clinics \\
& Difference over time $(95 \% \mathrm{Cl})$ & Difference over time $(95 \% \mathrm{Cl})$ \\
\hline Gini coefficient & $0.002(-0.004,0.007)$ & $-0.002(-0.004,0.008)$ \\
Concentration index & $0.006(-0.008,0.021)$ & $0.037(0.013,0.060)$ \\
$\mathrm{mKPI}$ & $-0.005(-0.010,0.019)$ & $-0.039(-0.064,-0.014)$ \\
\hline
\end{tabular}

Cl confidence interval, $\mathrm{mKPI}$ modified Kakwani Progressivity Index

very small; this is common for outcomes (such as vaccination completion) where the health equity gradient from low- to high-income is narrow at baseline.

\section{Conclusions}

Overall, our study suggests that a P4P incentive program was effective at maintaining SES-related health equity in vaccination completion, but did not improve it. Given how few studies address equity in the delivery of primary care, future research should take into consideration not only whether primary care renewal initiatives have an impact on health, but also the role of social determinants in driving inequities in health and health care use.

\section{Abbreviations}

Cl: Confidence interval; HIPC: Health Information Privacy Committee; HREB: Health Research Ethics Board; KPI: Kakwani Progressivity Index; MCHP: Manitoba Centre for Health Policy; MHHLS: Manitoba Health, Healthy Living and Seniors; mKPI: modified KPI; PIN: Physician Integrated Network; PATHS: Pathways to Health and Social Equity for Children; P4P: Pay-forperformance; SES: Socioeconomic status.

\section{Competing interests}

The authors declare that they have no competing interests.

\section{Authors' contributions}

AK, MB, DC, and the other members of the PATHS Equity Team contributed to the conception and design of the study. AK and members of the PATHS Equity Team were involved in data acquisition. $C T$ and DC conducted the data analysis, and all other authors participated in the interpretation of the data. AK and JEE drafted the manuscript and revised it with input from all other authors. All authors read and approved the final version of the manuscript.

\section{Acknowledgements}

This work was supported by the Canadian Institutes of Health Research (CIHR) grant FRN 115206 and the Heart \& Stroke Foundation of Canada grant PG-12-0534. We are indebted to Health Information Management, Manitoba Health, Healthy Living and Seniors (HIPC\#2011/2012-24-D), the Manitoba Immunization Monitoring System, and the Manitoba Health Registry for provision of data. We acknowledge the Manitoba Centre for Health Policy for use of data contained in the Population Health Research Data Repository. The results and conclusions are those of the authors and no official endorsement by the data providers is intended or should be inferred. At the time of this work, Dr. Patricia Martens was supported by $\mathrm{CIHR}$ and the Public Health Agency of Canada (PHAC) for her CIHR/PHAC Applied Public Health Research Chair (2008-2014). Dr. Marni Brownell acknowledges the financial support of the Government of Manitoba through the MCHP Population-Based Child Health Research Award. Dr. Alan Katz acknowledges funding from the Heart and Stroke Foundation and Research Manitoba in support of his Primary Prevention Research Chair. We also acknowledge Andrea Kroeker for her assistance with manuscript preparation. PATHS Equity Team members: James Bolton; Marni Brownell; Charles Burchill; Elaine Burland; Mariette Chartier; Dan Chateau; Malcolm Doupe; Jennifer E. Enns; Greg Finlayson; Randall Fransoo; Chun Yan Goh; Milton Hu; Doug Jutte; Alan Katz; Laurence Katz; Lisa Lix; Patricia J. Martens*; Colleen Metge; Nathan
C. Nickel; Colette Raymond; Les Roos; Noralou Roos; Rob Santos; Joykrishna Sarkar; Mark Smith; Carole Taylor; Randy Walld *deceased

\section{Author details}

${ }^{1}$ Manitoba Centre for Health Policy, 408-727 McDermot Ave, Winnipeg, MB R3E 3P5, Canada. ${ }^{2}$ Department of Community Health Sciences, University of Manitoba, S113-750 Bannatyne Ave, Winnipeg, MB R3E 0W3, Canada. ${ }^{3}$ School of Public Health, University of California, 50 University Hall, \#7360, Berkeley, CA 94720-7360, USA. "Winnipeg Regional Health Authority, Primary Health Care and Chronic Disease, 496 Hargrave St, Winnipeg, MB R3A 0X7, Canada. ${ }^{5}$ Winnipeg Regional Health Authority, 200-1155 Concordia Ave, Winnipeg, MB R2K 2M9, Canada.

Received: 30 June 2015 Accepted: 2 October 2015

Published online: 30 November 2015

\section{References}

1. Victora CG, Wagstaff A, Schellenberg JA, Gwatkin D, Claeson M, Habicht JP. Applying an equity lens to child health and mortality: more of the same is not enough. Lancet. 2003;362(9379):233-41.

2. World Health Organization. 10 Facts on Health Inequities and their Causes. Geneva: World Health Organization; 2011.

3. Roos NP, Sullivan K, Walld R, MacWilliam L. Potential savings from reducing inequalities in health. Can J Public Health. 2004:95(6):460-4.

4. Chumney EC, Mauldin PD, Simpson KN. Charges for hospital admissions attributable to health disparities for African-American patients, 1998-2002. J Natl Med Assoc. 2006;98(5):690-4.

5. Mackenbach JP, Meerding WJ, Kunst AE. Economic costs of health inequalities in the European Union. J Epidemiol Community Health. 2011;65(5):412-9.

6. Schoeni RF, Dow WH, Miller WD, Pamuk ER. The economic value of improving the health of disadvantaged Americans. Am J Prev Med. 2011:40(1 Suppl 1):S67-72.

7. Mills C, Reid P, Vaithianathan R. The cost of child health inequalities in Aotearoa New Zealand: a preliminary scoping study. BMC Public Health. 2012;12:384

8. Poulton R, Caspi A, Milne BJ, Thomson WM, Taylor A, Sears MR, et al. Association between children's experience of socioeconomic disadvantage and adult health: a life-course study. Lancet. 2002;360(9346):1640-5.

9. National Collaborating Centre for Healthy Public Policy. Thirteen Public Interventions in Canada that have Contributed to a Reduction in Health Inequities: Summary Report. Montreal, QC: National Collaborating Centre for Healthy Public Policy; 2010.

10. World Health Organization. World Conference on Social Determinants of Health: Case studies on social determinants. Geneva: World Health Organization; 2014.

11. Nickel NC, Chateau DG, Martens PJ, Brownell MD, Katz A, Burland EM, et al. Data resource profile: Pathways to Health and Social Equity for Children (PATHS Equity for Children). Int J Epidemiol. 2014;43(5):1438-49.

12. Katz A, Bogdanovic B, Soodeen R. Physician Integrated Network Baseline Evaluation: Linking Electronic Medical Records and Administrative Data. Winnipeg, MB: Manitoba Centre for Health Policy; 2010.

13. Hilderman T, Katz A, Derksen S, McGowan K, Chateau D, Kurbis C, et al. Manitoba Immunization Study. Winnipeg, MB: Manitoba Centre for Health Policy; 2011.

14. Public Health Agency of Canada. Immunizations and Vaccines: Canadian Immunization Guide. Available at: http://www.phac-aspc.gc.ca/publicat/ciggci/index-eng.php. Accessed May 14, 2015. 
15. You D, Wardlaw $T$, Salama $P$, Jones $G$. Levels and trends in under-5 mortality, 1990-2008. Lancet. 2010;375(9709):100-3.

16. Shepherd JE, Grabenstein JD. Immunizations for high-risk populations. J Am Pharm Assoc (Wash). 2001;41(6):839-49.

17. Crawford NW, Bines JE, Royle J, Buttery JP. Optimizing immunization in pediatric special risk groups. Expert Rev Vaccines. 2011;10(2):175-86.

18. Canavan ME, Sipsma HL, Kassie GM, Bradley EH. Correlates of complete childhood vaccination in East African countries. PLoS One. 2014;9(4):e95709.

19. Doherty $E$, Walsh B, O'Neill C. Decomposing socioeconomic inequality in child vaccination: results from Ireland. Vaccine. 2014;32(27):3438-44.

20. Dummer TJ, Cui Y, Strang R, Parker L. Immunization completeness of children under two years of age in Nova Scotia, Canada. Can J Public Health. 2012;103(5):e363-7.

21. Mathew JL. Inequity in childhood immunization in India: a systematic review. Indian Pediatr. 2012;49(3):203-23.

22. Rieck T, Feig M, Eckmanns T, Benzler J, Siedler A, Wichmann O. Vaccination coverage among children in Germany estimated by analysis of health insurance claims data. Hum Vaccin Immunother. 2014;10(2):476-84.

23. Ueda M, Kondo N, Takada M, Hashimoto H. Maternal work conditions, socioeconomic and educational status, and vaccination of children: a community-based household survey in Japan. Prev Med. 2014;66:17-21.

24. Williams IT, Milton JD, Farrell JB, Graham NM. Interaction of socioeconomic status and provider practices as predictors of immunization coverage in Virginia children. Pediatrics. 1995;96(3 Pt 1):439-46.

25. Fadnes LT, Jackson D, Engebretsen IM, Zembe W, Sanders D, Sommerfelt $H$, et al. Vaccination coverage and timeliness in three South African areas: a prospective study. BMC Public Health. 2011;11:404.

26. Jeong YW, Park BH, Kim KH, Han YR, Go UY, Choi WS, et al. Timeliness of MMR vaccination and barriers to vaccination in preschool children. Epidemiol Infect. 2011;139(2):247-56.

27. Odusanya OO, Alufohai EF, Meurice FP, Ahonkhai VI. Determinants of vaccination coverage in rural Nigeria. BMC Public Health. 2008;8:381.

28. Rosenthal J, Rodewald L, McCauley M, Berman S, Irigoyen M, Sawyer M, et al. Immunization coverage levels among 19- to 35-month-old children in 4 diverse, medically underserved areas of the United States. Pediatrics. 2004;113(4):e296-302.

29. Roos LL, Nicol JP. A research registry: uses, development, and accuracy. J Clin Epidemiol. 1999;52(1):39-47.

30. Roos LL, Gupta S, Soodeen RA, Jebamani L. Data quality in an information-rich environment: Canada as an example. Can J Aging. 2005;24 Suppl 1:153-70.

31. Roos LL, Brownell M, Lix L, Roos NP, Walld R, MacWilliam L. From health research to social research: privacy, methods, approaches. Soc Sci Med. 2008;66(1):117-29.

32. Jutte DP, Roos NP, Brownell MD, Briggs G, MacWilliam L, Roos LL. The ripples of adolescent motherhood: social, educational, and medical outcomes for children of teen and prior teen mothers. Acad Pediatr. 2010;10(5):293-301.

33. Katz A, Chateau D, Bogdanovic B, Taylor C, McGowan K, Rajotte L, et al. Physician Integrated Network: A Second Look. Winnipeg, MB: Manitoba Centre for Health Policy; 2014.

34. Gini C. Concentration and dependency ratios. Rivista di Politica Economica. 1997;87:769-89.

35. Kakwani N, Wagstaff A, van Doorslaer E. Socioeconomic inequalities in health: Measurement, computation, and statistical inference. J Econom. 1997;77:87-103.

36. Nickel NC, Martens PJ, Chateau D, Brownell MD, Sarkar J, Goh CY, et al. Have we left some behind? Trends in socio-economic inequalities in breastfeeding initiation: a population-based epidemiological surveillance study. Can J Public Health. 2014;105(5):e362-8.

37. Martens P, Brownell M, Au W, MacWilliam L, Prior H, Schultz J, et al. Health inequities in Manitoba: Is the socioeconomic gap widening or narrowing over time? Winnipeg, MB: Manitoba Centre for Health Policy; 2010.

38. O'Donnell O, van Doorslaer E, Wagstaff A, Lindelow M. Analyzing Health Equity Using Household Survey Data: A Guide to Techniques and their Implementation. Washington, DC: World Bank; 2008.

39. Dixon PM, Weiner K, Mithell-Olds T, Woodley R. Bootstrapping the Gini coefficient of inequality. Ecology. 1987;68:1548-51.

40. Institute SAS. SAS. Cary, NC: SAS Institute; 2011.

41. Huang J, Yin S, Lin Y, Jiang Q, He Y, Du L. Impact of pay-for-performance on management of diabetes: a systematic review. J Evid Based Med. 2013;6(3):173-84.
42. Scott A, Sivey P, Ait OD, Willenberg L, Naccarella L, Furler J, et al. The effect of financial incentives on the quality of health care provided by primary care physicians. Cochrane Database Syst Rev. 2011;9:CD008451.

43. Li J, Hurley J, DeCicca P, Buckley G. Physician response to pay-for-performance: evidence from a natural experiment. Health Econ. 2014;23(8):962-78.

44. Mullen KJ, Frank RG, Rosenthal MB. Can you get what you pay for? Pay-for-performance and the quality of healthcare providers. Rand J Econ. 2010;41(1):64-91.

45. Chien AT, Li Z, Rosenthal MB. Improving timely childhood immunizations through pay for performance in Medicaid-managed care. Health Serv Res. 2010;45(6 Pt 2):1934-47.

46. Raphael D. Social determinants of health: present status, unanswered questions, and future directions. Int J Health Serv. 2006;36(4):651-77.

47. Marmot M. Social determinants of health inequalities. Lancet. 2005;365(9464):1099-104.

48. Glidewell L, West R, Hackett JE, Carder P, Doran T, Foy R. Does a local financial incentive scheme reduce inequalities in the delivery of clinical care in a socially deprived community? A longitudinal data analysis. BMC Fam Pract. 2015;16:61.

49. Priedeman SM, Curtis SL, Basinga P, Angeles G. An equity analysis of performance-based financing in Rwanda: are services reaching the poorest women? Health Policy Plan. 2013;28(8):825-37.

50. Weissman JS, Hasnain-Wynia R, Weinick RM, Kang R, Vogeli C, lezzoni L, et al. Pay-for-performance programs to reduce racial/ethnic disparities: what might different designs achieve? J Health Care Poor Underserved. 2012;23(1):144-60.

51. Mustard CA, Derksen S, Berthelot JM, Wolfson M. Assessing ecologic proxies for household income: a comparison of household and neighbourhood level income measures in the study of population health status. Health Place. 1999;5(2):157-71.

\section{Submit your next manuscript to BioMed Central and take full advantage of:}

- Convenient online submission

- Thorough peer review

- No space constraints or color figure charges

- Immediate publication on acceptance

- Inclusion in PubMed, CAS, Scopus and Google Scholar

- Research which is freely available for redistribution 